\title{
The Critical Role of Iron in Host-Bacterial Interactions
}

\author{
Shelley M. Payne and Richard A. Finkelstein, Department of Microbiology, \\ The University of Texas Southwestern Medical School, Dallas, Texas 75235
}

A B S T RACT The ability of potential pathogens to acquire iron in a host is an important determinant of both their virulence and the nature of the infection produced. Virulent gram-negative bacteria are capable of acquiring sufficient iron from the host because their virulence (for chick embryos) is unaffected by exogenous iron. Avirulent mutants which are apparently limited in their ability to acquire iron could be isolated from the virulent strains. The lethality of these mutants was significantly enhanced by exogenous iron. Reduction of the relatively high serum iron saturation of chick embryos (to levels more closely approximating those in man) by pretreatment with ironbinding proteins or endotoxin inhibits the lethality of some virulent bacteria. Those bacteria whose virulence was reduced include the Shigella, Vibrio cholerae and strains of Neisseria gonorrhoeae, all of which are nondisseminating pathogens in the normal human host. Pathogens which produce septicemic and disseminating infections such as Neisseria meningitidis, Haemophilus influenzae type B, Escherichia coli possessing K-1 antigen, Pseudomonas aeruginosa and Salmonella typhimurium and disseminating strains of $N$. gonorrhoeae were, in general, unaffected by reduced serum iron saturation. These disseminating bacteria appeared to produce greater quantities of compounds (siderophores) which stimulated microbial growth in low-iron media than did the nondisseminating pathogens. Thus, the gram-negative bacteria tested can be divided into four major classes according to their responses to modifications in iron levels in the chick embryo model and these results correlate with the nature of the infections which they typically produce in man.

Dr. Payne was a National Science Foundation Predoctoral Fellow and these studies report portions of her dissertation submitted in partial fulfillment of the requirements for the degree of Doctor of Philosophy from University of Texas Health Science Center at Dallas. Her present address is Department of Biochemistry, The University of California, Berkeley, Calif. 94720.

Received for publication 17 November 1977 and in revised form 26 January 1978.

\section{INTRODUCTION}

Iron is essential for microbial growth but the acquisition of this element is particularly difficult for pathogens attempting to establish infections in mammalian hosts in which free iron is virtually nonexistent. Iron in the human body is primarily intracellular. The small quantity of iron in body fluids - the iron for which microorganisms must compete-is held by high affinity iron-binding proteins. Transferrin, the ironbinding protein of serum (1), and lactoferrin, a similar protein found in secretions (2), are normally unsaturated and limit the availability of iron both in the blood and on mucosal surfaces.

The presence of unsaturated iron-binding proteins has been shown repeatedly to contribute to the bacteriostatic and bactericidal qualities of serum and secretions (3-5). The addition of sufficient iron to saturate the protein iron-binding sites abolishes the inhibitory effect and allows growth of the microorganisms. Alterations in the levels of iron and ironbinding proteins in vivo might, therefore, be expected to influence the susceptibility of the host to infection.

Exogenous iron has been found to promote infection in a variety of experimental systems. Iron-treated animals are more susceptible to infection with a variety of pathogenic microorganisms than untreated animals $(3,4,6)$. Bacteria whose virulence has been shown to be enhanced by iron include Escherichia coli, Klebsiella pneumoniae, Pseudomonas aeruginosa, Listeria monocytogenes, Staphylococcus aureus, Bacillus anthracis, Yersinia pestis, Mycobacterium tuberculosis, and Neisseria gonorrhoeae.

There is also evidence that iron overload or increased serum iron saturation predisposes human beings to infection $(7,8)$. The incidence of bacterial infections is significantly increased in diseases associated with high serum iron saturation such as kwashiorkor (9) and acute myelogenous leukemia (10). On the other hand, procedures that reduce the availability of iron increase the resistance of the host to infection. Thus, mice fed an iron-deficient diet were less susceptible to infection with Salmonella typhimurium than control mice (11). 
Exposure to endotoxin, which enhances resistance to infection, reduces serum iron saturation (12). The administration of iron abolishes the protective effect (13).

To acquire their essential iron, bacteria produce iron-chelating compounds, or siderophores, which are extremely efficient in removing ferric iron from the environment and making it available for growth of the organism (14). These compounds have been shown to enhance virulence of $E$. coli and Salmonella for experimental animals $(15,16)$. Little is known concerning iron metabolism in many other pathogenic genera.

We had previously demonstrated that iron affected virulence of gonococci in the chick embryo model (6). Our present observations indicate that gramnegative pathogens can be divided into groups on the basis of their responses to iron modification in the chick embryo model and further suggest that these results are correlated with the nature of the infections which they typically produce in man.

\section{METHODS}

Bacterial strains. Bacterial strains and their sources are listed in Table 1. All strains were maintained by lyophilization in $10 \%$ skim milk (Difco Laboratories, Detroit, Mich.) and by storage at $-70^{\circ} \mathrm{C}$ in Trypticase soy broth (Baltimore Biological Laboratories, Baltimore, Md.) with $20 \%$ glycerol.

Media. Imferon agar (Merrell-National Laboratories, Cincinnati, Ohio) (17) was routinely used for growth of Neisseria strains. Chocolate agar (Randolph Biologicals, Dallas, Tex.) was utilized for growth of Haemophilus influenzae and Trypticase soy agar was used for all other strains.

The composition of conalbumin agar, used for the detection of iron-chelating compounds, varied with the bacterial species being tested. For gonococci and meningococci, GC base (Difco Laboratories) with $1 \%$ supplement (18) omitting the ferric nitrate was used and either 400 or $800 \mu \mathrm{g} / \mathrm{ml}$ "iron-free" conalbumin (type I, Sigma Chemical Co. St. Louis, Mo.) was added. Minimal agar (19) with 500 or $1,000 \mu \mathrm{g} / \mathrm{ml}$ conalbumin was employed for $P$. aeruginosa, E. coli and most Salmonella strains. Bacto peptone, $0.1 \%$ (Difco Laboratories), was added to this medium for assays involving Shigella and some Salmonella. A simple, chemically defined medium (20) without added iron or manganese (herein called Synbase to distinguish it from Syncase medium, which has added casamino acids) was utilized for growth of Vibrio cholerae. A $10-\mathrm{mg} / \mathrm{ml}$ solution of conalbumin was sterilized by filtration through a $0.22-\mu \mathrm{m}$ Millipore filter (Millipore Corp., Bedford, Mass.) and added aseptically to the sterile agar immediately before pouring the plates.

Bacterial strains were grown in low-iron media to stimulate the production of iron-chelating compounds (14). A biphasic medium consisting of GC conalbumin agar overlaid with an equal volume of the same medium lacking agar and starch was used for growth of gonococci, and meningococci were grown in Frantz medium (21). Other strains were grown in minimal medium with or without peptone or in Synbase as indicated above. Iron limitation was achieved by adding an excess of sterile iron-free conalbumin to bind the available iron. The conalbumin iron complexes were removed by ultrafiltration through PM-10 membranes (Amicon Corp., Scientific Sys. Div., Lexington Mass.).
Alternatively, excess iron was removed by Chelex 100 (BioRad Laboratories, Richmond, Calif.) ion exchange resin (22). The final iron concentration was $<0.05 \mu \mathrm{g} / \mathrm{ml}$ as determined by the method of Stookey (23) using ferrozine (United States Biochemical Corp., Cleveland Ohio).

Iron chelator assays. An agar plate technique similar to those described by Miles and Kjimji (24) and by Kochan et al. (25) was used as a biological assay for the detection of iron chelators or compounds that promote the growth of bacteria in low-iron media. Approximately $5 \times 10^{3}$ to $10^{4}$ indicator bacteria/ml were added to sterile molten conalbumin agar. For individual experiments, two concentrations of conalbumin and at least two levels of the indicator bacterial strain were used. Under the proper conditions, growth of the indicator strains is almost completely suppressed by the iron-limiting effects of conalbumin.

Strains were assayed for their ability to stimulate growth by dropping $10 \mu \mathrm{l}$ of a log phase broth culture $\cong 10^{9}$ bacteria/ml) on the surface of the seeded conalbumin agar plate. Plates were incubated and examined at 18 and $24 \mathrm{~h}$ for growth of the indicator strains around the test colony. Culture filtrates, purified chelators, and iron compounds were tested by cutting $5-\mathrm{mm}$ wells in the seeded agar and adding known volumes of the test solution to the wells.

Culture filtrates were also assayed for the presence of ironchelating compounds, siderophores, by a modification of the procedure of Macham and Ratledge (26) which depends on the ability of siderophores to solubilize iron at neutral $\mathrm{pH}$. ${ }^{59} \mathrm{FeCl}_{3}$ (New England Nuclear Boston, Mass.) in $0.1 \mathrm{M} \mathrm{HCl}$ was added to a sample of the culture filtrate and dialyzed (Spectrophore membrane tubing, 3, Spectrum Medical Industries, Inc., Los Angeles, Calif.) against $10 \mathrm{vol}$ of uninoculated culture medium. Samples of the dialysate were counted in a gamma counter (Searle Analytic, Inc., Des Plaines, Ill., model 1185) after $24 \mathrm{~h}$ and compared to standard solutions of ${ }^{59} \mathrm{Fe}$ to determine the amount of iron solubilized. Uninoculated medium containing ${ }^{59} \mathrm{Fe}$ alone or with a known amount of the iron chelator, Desferal (provided by B. R. Byers, University of Mississippi, Medical Center, Jackson, Miss.), were included in each experiment as negative and positive controls, respectively.

Partial purification of chelators. Presumed iron-chelating compounds were concentrated and partially purified by the ethyl acetate extraction procedure of Rodgers (15).

Chick embryo methodology. Chick embryos, strain 231 Leghorn, obtained from DeKalb Ag Research, Paris, Tex., were used essentially as described (6,27-29). 11-day embryos were inoculated intravenously, allantoically, or on the chorioallantoic membrane (CAM). The route of inoculation depended upon the bacterial species, as some bacteria are more virulent by one route than another. A minimum of six embryos was used per dose of bacteria and (or) iron or iron-binding compound, and experiments were considered valid only when none of the control embryos, i.e. those receiving only diluent or diluent containing the test compound, succumbed. Imferon, an iron-dextran compound containing $50 \mathrm{mg} \mathrm{Fe} / \mathrm{ml}$, was the usual source of iron for in vivo experiments. The ironbinding protein conalbumin (Sigma Chemical Co.) was used in both the iron-free (type I) and iron-complexed (type II) forms. Median lethan dose $\left(\mathrm{LD}_{50}\right)^{1}$ values were calculated according to Reed and Muench (30). Preparation of inocula, determination of bacteremic levels and assessment of growth in the allantoic cavity have been described (6).

${ }^{1}$ Abbreviations used in this paper: CAM, chorioallantoic membrane; CFU, colony forming units; DGI, disseminated gonococcal infections; $\mathrm{LD}_{50}$, median lethal dose; LPS, lipopolysaccharide. 
TABLE I

Bacterial Strains, Their Characteristics and Sources

\begin{tabular}{|c|c|c|}
\hline \multicolumn{3}{|c|}{ Neisseria gonorrhoeae } \\
\hline F62 & Colony types $\mathrm{T} 1, \mathrm{~T} 2, \mathrm{~T} 3, \mathrm{~T} 4$ & D. S. Kellogg \\
\hline 2686 & Colony types $\mathrm{T} 1, \mathrm{~T} 4$ & T. M. Buchanan \\
\hline 1975 & DGI & S. Falkow \\
\hline NRL 6555 & DGI ) & \\
\hline NRL 6558 & DGI & K. K. Holmes \\
\hline CDC 5 & & \\
\hline \multicolumn{3}{|c|}{ Neisseria meningitidis } \\
\hline \multicolumn{3}{|c|}{ A-17 ] } \\
\hline B-11 & & H. Schneider \\
\hline \multicolumn{3}{|l|}{ C-11 } \\
\hline \\
\hline $\mathrm{Z}\}$ & & Local isolate \\
\hline A-17 $\mathrm{CR}^{-*}$ & & NTG mutagenesis of A-17 \\
\hline B-11 CR- & & NTG mutagenesis of B-11 \\
\hline Neisseria sicca & & K. H. Johnston \\
\hline Neisseria subflava & & K. H. Johnston \\
\hline \multicolumn{3}{|c|}{ Haemophilus influenzae } \\
\hline type B & & G. McCracken, Jr. \\
\hline \multicolumn{3}{|c|}{ Pseudomonas aeruginosa } \\
\hline P2 ) & & \\
\hline P3A & & Charles Baxter \\
\hline P3B & & \\
\hline \multicolumn{3}{|l|}{ Shigella flexneri } \\
\hline 2457 & $\mathrm{O}$ and $\mathrm{T}$ colony types & \\
\hline G $108-1-13$ & S. flexneri-E. coli hybrid & S. B. Formal \\
\hline \multicolumn{3}{|l|}{ Shigella dysenteriae } \\
\hline WR 377 & $\mathrm{CR}^{+}$and $\mathrm{CR}^{-}$colony types & R. Wedgwood \\
\hline \multicolumn{3}{|l|}{ Escherichia coli } \\
\hline $\begin{array}{l}\text { U169 } \\
\text { C98 }\end{array}$ & $\mathrm{Kl}^{+} ; \mathrm{CR}^{+}$and $\mathrm{CR}^{-}$colony types & G. McCracken, Jr. \\
\hline 711 & & S. Falkow \\
\hline \multicolumn{3}{|c|}{ Salmonella typhimurium } \\
\hline LT 7 & & P. Gemski \\
\hline \multicolumn{3}{|l|}{ Vibrio cholerae } \\
\hline 569B & & N. K. Dutta \\
\hline 569B CR- & & NTG mutagenesis of $569 \mathrm{~B}$ \\
\hline NIH $35 \mathrm{~A} 3$ & & Walter Reed Army Inst. of \\
\hline NIH 41 & & Research, Wash., D. C. \\
\hline HP-55-1 (El tor) & & $\begin{array}{l}\text { Korat, Thailand, } \\
\text { R. A. Finkelstein }\end{array}$ \\
\hline \multicolumn{3}{|l|}{ Yersinia pestis } \\
\hline $\begin{array}{l}2 \mathrm{C} \\
25\end{array}$ & & Robert Brubaker \\
\hline
\end{tabular}

* Does not absorb Congo red from agar media (33).

Serum iron levels and latent iron-binding capacity, a measure of the unsaturated iron-binding sites, were determined by the method of Persijn et al. (31) using half the recommended volumes.

\section{RESULTS}

As was noted (6), virulent colony types of gonococci, $\mathrm{T} 1$ and $\mathrm{T} 2$, were found to be capable of accpuiring suf- 
ficient iron from the chick embryo in that they could multiply and cause lethal infections from small inocula, whereas the avirulent colony types, T3 and T4, required exogenous iron for virulence. Like virulent gonococci, virulent strains of Shigella flexneri, E. coli, $V$. cholerae, and $N$. meningitidis were equally lethal in the presence or absence of exogenous iron (Table II) and it is concluded that these bacteria are able to acquire sufficient iron in the normal chick embryo to support their multiplication and permit expression of their pathogenicity.

In contrast, an opaque colonial variant of $S$. flexneri 2457 which is avirulent for man (32) was found in this study to be relatively avirulent for allantoically inoculated 11-day chick embryos. Other mutants selected from virulent strains on the basis of their inability to absorb the dye Congo red (33) were also found to be less virulent for chick embryos than the parent strain, but their virulence was increased significantly when the inoculum was supplemented with iron (Table III). Iron enhanced virulence of the mutants when it was given simultaneously with the inoculum by the same route or when it was administered intravenously 1 to $24 \mathrm{~h}$ before allantoic or chorioallantoic challenge.

Not all avirulent bacteria tested responded to the addition of iron. Two nonpathogenic Neisseria ( $N$. sicca and $N$. subflava), a strain of $E$. coli K-12, a S. flexneri-E. coli hybrid and several Y. pestis mutants

TABLE II

Lack of Effect of Iron on Lethality of Virulent Bacteria for Chick Embryos

\begin{tabular}{llll}
\hline \multicolumn{1}{c}{ Inoculum } & \multicolumn{1}{c}{$\begin{array}{c}\text { Iron } \\
\text { source }\end{array}$} & $\begin{array}{c}\text { LD }_{\text {so }} \\
\text { control }\end{array}$ & $\begin{array}{c}\text { LD }_{\text {so }} \\
\text { with iron }\end{array}$ \\
\hline N. gonorrhoeae & & & \\
F62 T1 (i.v.) & FAC $\ddagger$ & $7.0 \times 10^{\circ} \S$ & $1.7 \times 10^{1}$ \\
F62 T1 (i.v.) & Imferon" & $3.2 \times 10^{\circ}$ & $2.5 \times 10^{1}$ \\
2686 T1 (i.v.) & FAC & $1.9 \times 10^{\circ}$ & $1.0 \times 10^{\circ}$ \\
2686 T1 (i.v.) & Imferon & $1.9 \times 10^{\circ}$ & $1.0 \times 10^{\circ}$ \\
N. meningitidis & & & \\
$\quad$ A-17 (CAM) & Imferon & $3.2 \times 10^{3}$ & $5.2 \times 10^{2}$ \\
$\quad$ A-17 (i.v.) & Imferon & $1.0 \times 10^{\circ}$ & $1.0 \times 10^{\circ}$ \\
S. flexneri & & & \\
2457 T (allantoic) & Imferon & $6.3 \times 10^{\circ}$ & $1.1 \times 10^{\circ}$ \\
E. coli & & & \\
U169 (CAM) & Imferon & $2.0 \times 10^{1}$ & $2.0 \times 10^{1}$ \\
V. cholerae & & & \\
$\quad$ NIH 41 (allantoic) & Imferon & $1.0 \times 10^{\circ}$ & $1.0 \times 10^{\circ}$ \\
\hline
\end{tabular}

* Route of inoculation.

$\$$ Ferric ammonium citrate, $62.5 \mu \mathrm{g} \mathrm{Fe}$.

$\S \mathrm{CFU}$.

" $500 \mu \mathrm{g} \mathrm{Fe}$.
TABLE III

Effect of Iron on Virulence of Relatively

Avirulent Mutants

\begin{tabular}{|c|c|c|c|c|}
\hline Inoculum & $\begin{array}{c}\text { Route of } \\
\text { inoculation }\end{array}$ & $\begin{array}{c}\text { LD }_{\text {so }} \\
\text { control }\end{array}$ & $\begin{array}{c}\text { LD }_{\text {so }} \\
\text { with iron* }\end{array}$ & $\begin{array}{l}\text { Fold increase } \\
\text { in virulence }\end{array}$ \\
\hline \multicolumn{5}{|l|}{ S. flexneri } \\
\hline 2457 O & allantoic & $5.1 \times 10^{5} t$ & $4.1 \times 10^{3}$ & 124 \\
\hline \multicolumn{5}{|l|}{ E. coli } \\
\hline U 169B & CAM & $3.1 \times 10^{4}$ & $1.2 \times 10^{2}$ & 258 \\
\hline \multicolumn{5}{|l|}{ N. meningitidis } \\
\hline A-17 CR- $\$$ & CAM & $3.0 \times 10^{5}$ & $4.7 \times 10^{3}$ & 64 \\
\hline B-11 CR ${ }^{-}$ & CAM & $2.9 \times 10^{5}$ & $2.3 \times 10^{3}$ & 126 \\
\hline \multicolumn{5}{|l|}{ V. cholerae } \\
\hline 569B CR ${ }^{-}$ & allantoic & $3.0 \times 10^{5}$ & $2.3 \times 10^{3}$ & 130 \\
\hline
\end{tabular}

* Imferon, $500 \mu \mathrm{g} \mathrm{Fe.}$

$\ddagger$ CFU.

$\$ \mathrm{CR}^{-}$, mutants selected as colorless colonies on Congo red agar (33).

were found to be avirulent for chick embryos $\left(\mathrm{LD}_{30}\right.$ $>10^{5}$ ) and their lethality was not influenced by the addition of iron. Thus it may be concluded that whereas iron may be essential for expression of virulence by some "avirulent" bacteria, it is not sufficient for virulence. Those strains or mutants whose virulence was enhanced by iron were, therefore, considered to comprise a distinct group and will be referred to as Class III bacteria (see Table XI), whereas those organisms which are avirulent even with added iron are regarded as Class IV.

Because increasing the availability of iron enhanced the virulence of some relatively avirulent mutants, the effect, on virulent organisms, of compounds which bind iron and thereby reduce its availability was determined. Conalbumin, an iron-binding protein found in chicken eggs, which is structurally and functionally similar to transferrin, was used in both the iron-free and iron-complexed forms. The intravenous administration of $500 \mu \mathrm{g}$ of iron-free conalbumin led to an increase in the iron-binding capacity of chick embryo serum (Table IV), decreasing the serum iron saturation from the relatively high 77 to $30 \%$, a level more closely related to that found in the human host.

A series of experiments demonstrated that virulent bacteria can be divided into two classes on the basis of their response to conalbumin treatment of the embryos. One group, which includes strains of $N$. gonorrhoeae, V. cholerae, and Shigella species, was significantly less virulent in the presence of conalbumin (Table V). This effect could be specifically attributed to iron deprivation because it was not observed when iron-complexed conalbumin was used or when iron compounds were administered in addition to the iron-binding protein. $\mathrm{LD}_{50}$ values were the same for inocula containing the bacteria alone or with the ironcomplexed protein. 
TABLE IV

Effect of Conalbumin on Serum Iron Saturation of 11-Day Chick Embryos

\begin{tabular}{|c|c|c|c|c|}
\hline & & & & Saturation \\
\hline & Serum iron & LIBC** & TIBCI & $\begin{array}{l}\text { Serum iron/ } \\
\text { TIBC }\end{array}$ \\
\hline & $\mu M$ & $\mu M$ & $\mu M$ & $\%$ \\
\hline Control & $\begin{array}{c}3.6 \S \\
(3.0-4.3)\end{array}$ & $\begin{array}{c}1.1 \\
(0.5-1.9)\end{array}$ & 4.7 & 77 \\
\hline $\begin{array}{l}\text { Conalbumin-treated, } \\
500 \mu g \text { iron-free }\end{array}$ & $\begin{array}{c}3.9 \\
(2.2-5.4)\end{array}$ & $\begin{array}{c}8.9 \\
(4.3-10.2)\end{array}$ & 12.8 & 30 \\
\hline T4 infectedף & $\begin{array}{c}2.1 \\
(1.6-3.0)\end{array}$ & $\begin{array}{c}3.2 \\
(2.5-4.1)\end{array}$ & 5.3 & 40 \\
\hline
\end{tabular}

* Latent iron-binding capacity.

$\$$ Total iron-binding capacity.

$\$$ Values are means (ranges) for 10 individual embryos per group.

"Administered i.v. 1-3 $\mathrm{h}$ before bleeding.

I $10^{5}$ CFU avirulent (T4) gonococci inoculated allantoically $24 \mathrm{~h}$ before bleeding.

It was found that the presence of conalbumin reduced the level of bacteremia in embryos infected with virulent gonococci (Fig. 1). There was no increase in the number of gonococci in the blood of conalbumin-treated embryos in the $12 \mathrm{~h}$ after inoculation, in contrast to the multiplication observed in untreated controls.
Those pathogens whose virulence was reduced by the iron-limiting effect of conalbumin were all nondisseminating pathogens in the human host. These bacteria have a limited capacity to invade host tissues and do not demonstrate a propensity to cause septicemic infections. Members of this group (Class II) differ from Class III strains in that they have a limited ability to acquire iron and only require additional amounts of this element when the serum iron saturation is low.

In contrast to the Class II bacteria described above, some virulent pathogens were found to be unaffected by addition of conalbumin. These bacteria, which form a separate class (Class I), include those that characteristically are capable of producing septicemic, disseminating infections in the natural host. Representatives of this class include $N$. meningitidis, $H$. influenzae type B, E. coli strains bearing the K-1 antigen, $P$. aeruginosa, and S. typhimurium. These bacteria were as lethal in embryos in which the serum iron saturation was $30 \%$ as in those with $80 \%$ saturated serum (Table VI, and Table IV). Neither the total number of embryos which succumbed nor the time of death as a result of infection with these pathogens was affected by conalbumin.

Interestingly, $N$. gonorrhoeae, regarded as a Class II organism, is occasionally associated with disseminated infections in man. When strains isolated from cases of disseminated gonococcal infections (DGI) were

TABLE V

Inhibition of Virulence by Conalbumin

\begin{tabular}{|c|c|c|c|c|}
\hline \multirow[b]{2}{*}{ Strain } & \multirow[b]{2}{*}{$\begin{array}{l}\text { Route of } \\
\text { inoculation }\end{array}$} & \multicolumn{2}{|c|}{$\mathrm{LD}_{\mathrm{s0}}$ at $24 \mathrm{~h}$} & \multirow[b]{2}{*}{$\begin{array}{l}\text { Fold decrease } \\
\text { in virulence }\end{array}$} \\
\hline & & Control & $\begin{array}{l}\text { with } \\
\text { conalbumin* }\end{array}$ & \\
\hline \multicolumn{5}{|l|}{ N. gonorrhoeae } \\
\hline F62 T1 & i.v. & $2.4 \times 10^{1} \ddagger$ & $1.1 \times 10^{4}$ & 450 \\
\hline $2686 \mathrm{~T} 1$ & i.v. & $1.0 \times 10^{\circ}$ & $3.0 \times 10^{2}$ & 300 \\
\hline \multicolumn{5}{|l|}{ V. cholerae } \\
\hline \multicolumn{5}{|c|}{ Classical Ogawa } \\
\hline NIH 41 & allantoic & $9.4 \times 10^{0}$ & $1.4 \times 10^{4}$ & 1,500 \\
\hline \multicolumn{5}{|c|}{ Classical Inaba } \\
\hline NIH 35A3 & allantoic & $4.9 \times 10^{1}$ & $9.8 \times 10^{3}$ & 200 \\
\hline \multicolumn{5}{|l|}{ E1 Tor Inaba } \\
\hline HP-55-1 & allantoic & $1.0 \times 10^{0}$ & $3.0 \times 10^{1}$ & 30 \\
\hline \multicolumn{5}{|l|}{ S. flexneri } \\
\hline $2457 \mathrm{~T}$ & allantoic & $2.4 \times 10^{1}$ & $1.6 \times 10^{4}$ & 667 \\
\hline S. dysenteriae & allantoic & $(14 / 28) \S$ & $(1 / 28) \S$ & - \\
\hline
\end{tabular}

* $500 \mu \mathrm{g}$ “iron-free."

† CFU.

$\S$ No. dead/total; $L_{50}$ value cannot be determined; number of deaths unrelated to inoculum size within the range of $10^{1}-10^{5} \mathrm{CFU}$. 




Figure 1 Effect of conalbumin on level of bacteremia after intravenous inoculation with Neisseria gonorrhoeae F62 T1. Each point represents the geometric mean of three determinations at specified times (hours) after inoculation.

evaluated for virulence in the presence of conalbumin, they (Table VI) were found to resemble more closely the naturally disseminating meningococci than ordinary urogenital isolates of gonococci (Table V). ${ }^{2}$

The avirulent mutants and colonial variants such as T4 gonococci were also relatively unaffected by conalbumin in the chick embryo. For example, $\mathrm{LD}_{50}$ values for $N$. gonorrhoeae $\mathrm{F} 62 \mathrm{~T} 4$ were $8.8 \times 10^{5}$ and 7.9 $\times 10^{5}$ in normal and conalbumin-treated embryos, respectively. The growth (and virulence) of these mutants is presumably already limited by the scarcity of iron and cannot be further inhibited by conalbumin.

The allantoic cavity of chick embryos is normally a favorable environment for bacterial growth. Examples of the first three classes of bacteria were grown in the allantoic cavity in the presence and absence of conalbumin to determine whether the inhibition of virulence was due to a bactericidal or bacteriostatic effect and to determine if the different responses of virulent bacteria in vivo would be reflected in different patterns of growth in the presence of the iron-binding protein. Both iron-free and ironcomplexed conalbumin were used.

Avirulent gonococci, which require exogenous iron for virulence, exhibited little or no growth in the presence of iron-free conalbumin (Fig. 2). Although the number of viable gonococci decreased in the first $4 \mathrm{~h}$ after inoculation, the effect of conalbumin appeared to be primarily bacteriostatic, rather than bactericidal. This inhibition of growth was apparently due to

\footnotetext{
${ }^{2}$ Payne, S. M., K. K. Holmes, and R. A. Finkelstein. Infect. Immun. In press.
}

iron deprivation because it did not occur when the conalbumin was saturated with iron (Fig. 2).

The virulent gonococci, whose lethality is inhibited by conalbumin, were also inhibited by iron-free but not iron-complexed conalbumin in the allantoic cavity (Fig. 3). Unlike the avirulent gonococci, however, the virulent gonococci were able to overcome this inhibition and resume growth after a lag of $\cong 8 \mathrm{~h}$.

A less marked inhibition was observed when meningococci (Class I) were grown in the presence of conalbumin (Fig. 4). No initial reduction in the number of bacteria was noted and growth proceeded after a comparatively brief lag.

Because endotoxin has been shown to increase resistance of the chick embryo to infection $(27,34)$, the possible participation of iron in endotoxin-mediated resistance was explored. Embryos were inoculated allantoically with $\mathrm{T} 4$ gonococci as a source of endotoxin. $24 \mathrm{~h}$ after inoculation, the serum iron levels were found to be lower in infected than in control embryos, and the infected embryos also exhibited an increase in their latent iron-binding capacity (Table IV). Although endotoxin decreases the serum iron levels rather than simply increasing the latent iron-

TABLE VI

Lack of Inhibition of Virulence by Conalbumin

\begin{tabular}{|c|c|c|c|}
\hline Strain & $\begin{array}{c}\text { Route of } \\
\text { inoculation }\end{array}$ & $\begin{array}{l}\mathrm{LD}_{\mathbf{s 0}} \\
\text { control }\end{array}$ & $\begin{array}{l}\mathrm{LD}_{\mathbf{s 0}} \text { with } \\
\text { conalbumin }\end{array}$ \\
\hline \multicolumn{4}{|l|}{ N. meningitidis } \\
\hline A-1-7 & i.v. & $1.1 \times 10^{0} \ddagger$ & $1.0 \times 10^{0}$ \\
\hline B-11 & i.v. & $1.7 \times 10^{\circ}$ & $1.7 \times 10^{0}$ \\
\hline C-11 & i.v. & $1.8 \times 10^{0}$ & $1.8 \times 10^{0}$ \\
\hline Group X & i.v. & $5.7 \times 10^{0}$ & $1.5 \times 10^{0}$ \\
\hline Group Z & i.v. & $3.7 \times 10^{0}$ & $6.9 \times 10^{0}$ \\
\hline A-1-7 & CAM & $1.2 \times 10^{3}$ & $2.2 \times 10^{2}$ \\
\hline \multicolumn{4}{|c|}{ N. gonorrhoeae (DGI) } \\
\hline 1975 & i.v. & $2.9 \times 10^{1}$ & $5.0 \times 10^{1}$ \\
\hline 6555 & i.v. & $4.5 \times 10^{0}$ & $4.8 \times 10^{\circ}$ \\
\hline 6558 & i.v. & $9.3 \times 10^{1}$ & $8.1 \times 10^{1}$ \\
\hline \multicolumn{4}{|l|}{ H. influenzae } \\
\hline Type B & i.v. & $4.0 \times 10^{0}$ & $4.0 \times 10^{0}$ \\
\hline \multicolumn{4}{|l|}{ E. coli, K1 } \\
\hline U169 & CAM & $4.8 \times 10^{1}$ & $4.8 \times 10^{1}$ \\
\hline C98 & CAM & $5.6 \times 10^{0}$ & $4.0 \times 10^{0}$ \\
\hline \multicolumn{4}{|l|}{ P. aeruginosa } \\
\hline $\mathrm{P} 2$ & i.v. & $1.6 \times 10^{0}$ & $1.6 \times 10^{0}$ \\
\hline P3A & i.v. & $1.2 \times 10^{0}$ & $2.0 \times 10^{0}$ \\
\hline P3B & i.v. & $1.1 \times 10^{0}$ & $1.1 \times 10^{0}$ \\
\hline \multicolumn{4}{|l|}{ S. typhimurium } \\
\hline LT 7 & i.v. & $1.0 \times 10^{0}$ & $1.0 \times 10^{\circ}$ \\
\hline
\end{tabular}

* $500 \mu \mathrm{g}$ "iron-free."

† CFU. 


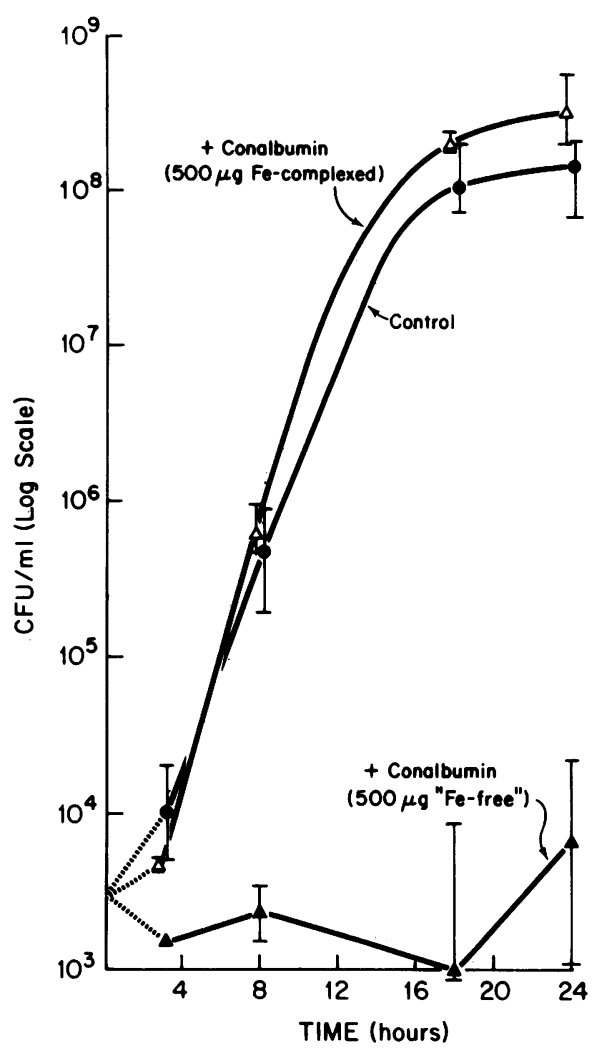

FIGURE 2 Effect of conalbumin on growth of Neisseria gonorrhoeae (F62 T3) in the allantoic cavity of 11-day chick embryos. Each point represents the mean of three determinations at specified times (hours) after inoculation.

binding capacity as does conalbumin, both treatments have the same overall effect, i.e., a significant decrease in the serum iron saturation. Similar results were obtained using heat-killed gonococcal cells or purified E. coli endotoxic lipopolysaccharide (LPS).

Inoculation of the embryos with live or heat-killed gonococcal cells or with $E$. coli endotoxin had a profound effect on the susceptibility of chick embryos to subsequent challenge with virulent bacteria. Pretreated embryos survived normally lethal doses of Class II bacteria, those with virulence was also inhibited by conalbumin (Table VII). This protective effect was reversed by the addition of iron to challenge inocula of gonococci, Shigella, or cholera vibrios.

Not all bacteria were responsive to the resistancepromoting effect of endotoxin. In general, embryos were protected against challenge with Class II bacteria but not against members of Class I (Table VIII). One exception was noted, however. A strain of $P$. aeruginosa which behaved like members of Class I in response to conalbumin treatment was inhibited by endotoxin treatment of the embryos. This inhibition of virulence was not reversible by iron, suggesting that more than one mechanism is involved in the resistance effected by endotoxin in the chick embryo.

A number of factors may contribute to the different responses of bacteria to alteration of host iron levels. The ability to produce a septicemic infection may require a more efficient production and utilization of ironchelating compounds, siderophores, then would be needed for a localized surface infection. The inability of Class III mutants to establish infection may indicate the absence of a functional chelator-mediated iron transport system.

Two assays were initially used to screen for the presence of siderophores in crude culture supernates and to determine the appropriate conditions for the production of these compounds in vitro. Samples were tested for their ability to stimulate growth of the homologous strain in conalbumin agar (Fig. 5). Additionally, ${ }^{59} \mathrm{FeCl}_{3}$ was added to samples of culture supernates and dialyzed against sterile uninoculated medium to assay for compounds capable of solubilizing the iron and converting it to a dialyzable form. Only

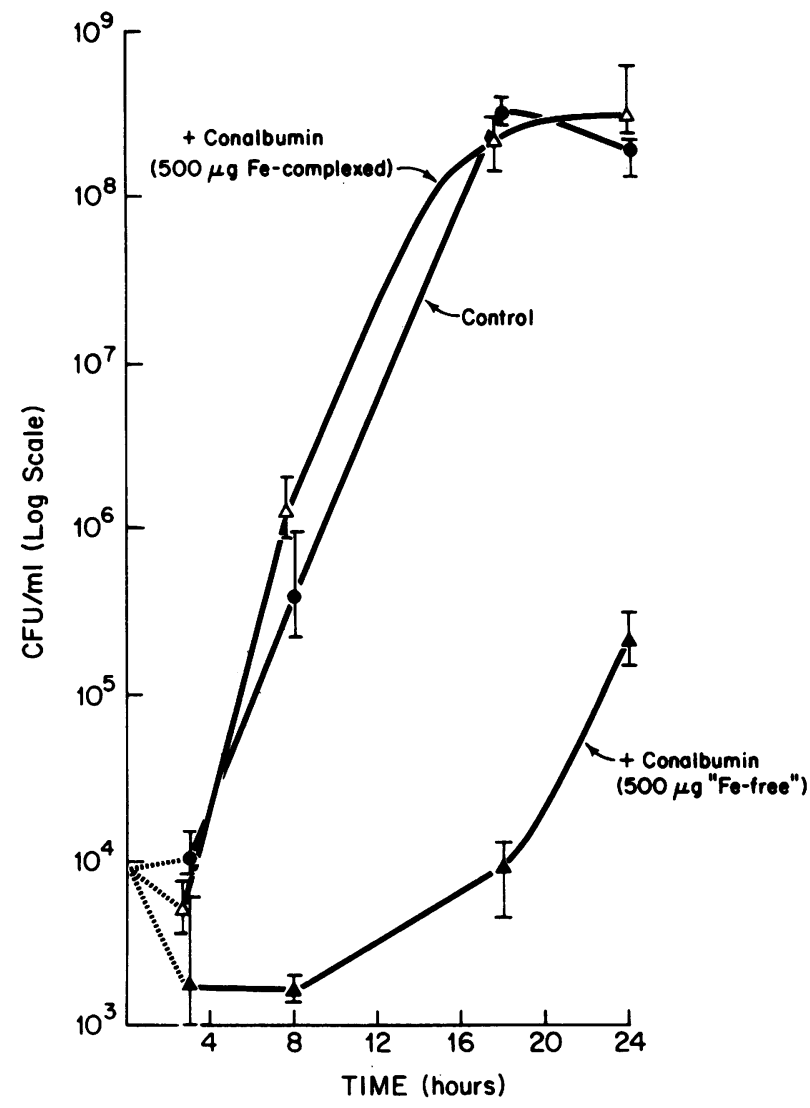

Figure 3 Effect of conalbumin on growth of Neisseria gonorrhoeae (F62 T1) in the allantoic cavity of 11-day chick embryos. Each point represents the mean of three determinations at specified times (hours) after inoculation. 


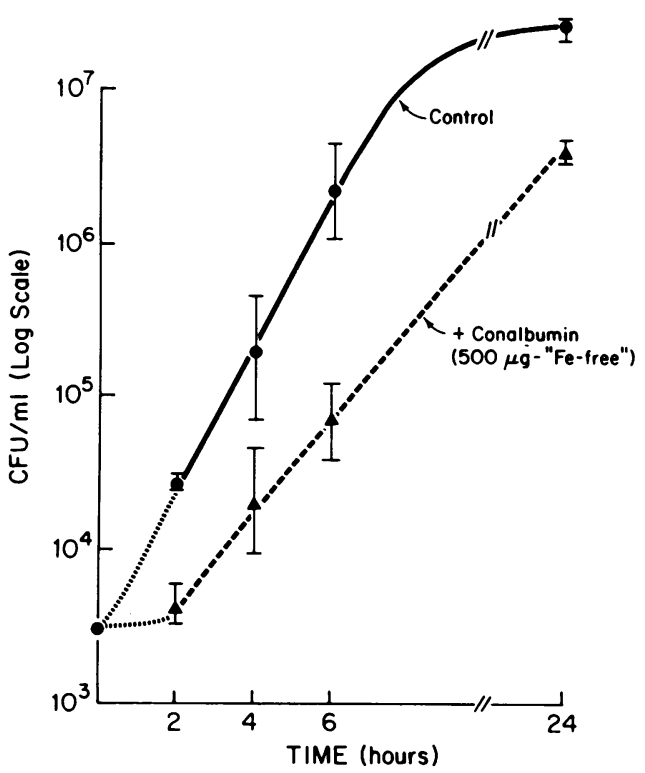

FIGURE 4 Effect of conalbumin on growth of Neisseria meningitidis ( $\mathrm{Gp} \mathrm{A}$, strain 17) in the allantoic cavity of 11-day chick embryos. Each point represents the mean of three determinations at specified times (hours) after inoculation.

those supernates that both stimulated growth and solubilized iron were used further.

Samples of each supernate were tested for stimulation of growth of heterologous as well as homologous strains (Table IX). With the exception of the gonococcus, siderophores produced by the strains tested were interchangeable and were active with all of the other indicator strains.

No stimulatory activity was detected in culture fil- trates of ordinary urogenital isolates of gonococci. However, strains which were isolated from disseminated gonococcal infections (and whose virulence for chick embryos was not inhibited by conalbumin) produced stimulatory activity which, unlike the factors produced by the other bacteria tested, was active only with gonococcal strains. No stimulation of growth was observed even when meningococci or cholera vibrios was used as the indicator, despite the fact that both of these groups produce compounds which stimulate growth of gonococci. No cross-stimulation was observed between gonococci and E. coli, Salmonella, or Shigella. This suggests that gonococci are unable to use enterochelin (enterobactin), the siderophore which is known to be produced by $E$. coli and Salmonella. This was confirmed by testing a sample of enterochelin provided by J. B. Neilands (University of California at Berkeley, Calif.) in conalbumin agar seeded with gonococci. No stimulation of gonococcal growth by enterochelin was observed, although the enterochelin sample stimulated growth of the other organisms tested.

Although no activity was detected in unconcentrated culture filtrates of nondisseminating gonococcal strains, activity was detected when the filtrate was extracted with ethyl acetate and concentrated 10- to 100-fold.

Using the conalbumin agar assay, differences were observed among virulent, Class I and Class II, strains. Class I strains appeared to produce greater amounts of their siderophores than did Class II strains using growth stimulation by dilutions of culture filtrate as a measure of siderophore production (Table X). Culture filtrates of the meningococcus and disseminated gonococcal infection strains, both Class I bacteria, were 80 -

TABLE VII

Reversal by Iron of Protective Effect of Pretreatment with Live or Heat-killed Gonococci or LPS

\begin{tabular}{|c|c|c|c|c|}
\hline $\begin{array}{c}\text { Challenge } \\
\text { (Route of inoculation) }\end{array}$ & Control & Pretreatment* & No iron & Iront \\
\hline \multicolumn{5}{|l|}{ N. gonorrhoeae (i.v.) } \\
\hline F62 T1 $\left(10^{3}\right)$ & $4 / 15(26) \S$ & F62 T4 $\left(10^{5}\right)$ & $11 / 15 \quad(73)$ & $2 / 15(13)$ \\
\hline F62 Tl $\left(10^{3}\right)$ & $1 / 12(8)$ & $\begin{array}{l}\text { F62 T4 }\left(10^{7}\right) \\
\text { (heat-killed) }\end{array}$ & $8 / 12 \quad(67)$ & $0 / 12 \quad(0)$ \\
\hline $\mathrm{F} 62 \mathrm{~T} 1\left(10^{2}\right)$ & $2 / 8 \quad(25)$ & $\begin{array}{l}\text { LPS (E. coli } \\
\quad \text { 055:B5 } 2 \mu \mathrm{g})\end{array}$ & (88) & $2 / 8 \quad(25)$ \\
\hline \multicolumn{5}{|l|}{ S. flexneri (allantoic) } \\
\hline $2457 \mathrm{~T}\left(10^{2}\right)$ & $0 / 7 \quad(0)$ & F62 T4 $\left(10^{4}\right)$ & $7 / 7 \quad(100)$ & $0 / 7$ \\
\hline \multicolumn{5}{|l|}{ V. cholerae (allantoic) } \\
\hline NIH $35 \mathrm{~A} 3\left(10^{3}\right)$ & $0 / 6 \quad(0)$ & F62 T4 $\left(10^{4}\right)$ & (67) & $1 / 6 \quad(17)$ \\
\hline
\end{tabular}

* Allantoic inoculation $24 \mathrm{~h}$ before challenge.

\$ $500 \mu \mathrm{g}$ iron (Imferon) added to challenge inocula.

\$ Survival: no./total (percent). 
TABLE VIII

Effect of Pretreatment with Live or Heat-Killed Gonococci or LPS on Virulence of Class I Strains

\begin{tabular}{|c|c|c|c|c|}
\hline $\begin{array}{l}\text { Challenge } \\
\text { (intravenous) }\end{array}$ & Control & Pretreatment* & No iron & Iron! \\
\hline \multicolumn{5}{|l|}{ N. meningitidis } \\
\hline A-1-7 $\left(10^{\circ}\right)$ & $5 / 7(71) \S$ & $\begin{array}{l}\text { F62 T4 }\left(10^{7}\right) \\
\quad \text { (heat-killed) }\end{array}$ & $5 / 7(71)$ & $5 / 7 \quad(71)$ \\
\hline A-1-7 $\left(10^{1}\right)$ & $7 / 8 \quad(88)$ & $\begin{array}{l}\text { LPS (E. coli } \\
\quad \text { 055:B5 } 2 \mu \mathrm{g})\end{array}$ & $7 / 8(88)$ & $8 / 8(100)$ \\
\hline A-1-7 $\left(10^{1}\right)$ & $8 / 8(100)$ & F62 T4 $\left(10^{5}\right)$ & $7 / 8(88)$ & $8 / 8(100)$ \\
\hline \multicolumn{5}{|c|}{ N. gonorrhoeae (DGI) } \\
\hline $6555\left(10^{1}\right)$ & $7 / 8 \quad(88)$ & $\begin{array}{l}\text { F62 T4 }\left(10^{7}\right) \\
\quad(\text { heat-killed })\end{array}$ & $7 / 8(88)$ & $7 / 8 \quad(88)$ \\
\hline $\begin{array}{l}\text { H. influenzae } \\
\text { type B }\left(10^{1}\right)\end{array}$ & $6 / 7 \quad(86)$ & $\begin{array}{l}\text { F62 T4 }\left(10^{7}\right) \\
\quad(\text { heat-killed) }\end{array}$ & $5 / 7(71)$ & $5 / 7 \quad(71)$ \\
\hline $\begin{array}{l}\text { P. aeruginosa } \\
\text { P2 }\left(10^{1}\right)\end{array}$ & $8 / 8(100)$ & $\begin{array}{l}\text { F62 T4 }\left(10^{7}\right) \\
\text { (heat-killed) }\end{array}$ & $1 / 8$ & $2 / 8 \quad(25)$ \\
\hline
\end{tabular}

* Allantoic inoculation $24 \mathrm{~h}$ before challenge.

$\$ 500 \mu \mathrm{g}$ iron (Imferon) added to challenge inocula.

$\S$ Mortality no./total (percent).

and 20-fold more active than culture filtrates of a nondisseminating Class II gonococcus. Similarly, E. coli and $S$. typhimurium were more active than $V$. cholerae and $S$. dysenteriae (Table $\mathrm{X}$ ). Comparisons of this type must be made with caution, however, because different growth media and conditions were used for the different bacteria.

Among Class III bacteria, Congo red ${ }^{-}$mutants produced similar amounts of siderophore activity as their virulent parents but appeared to be less able to respond to added siderophores. No obvious differences were noted in siderophore production or utilization by avirulent gonococcal colony types in comparison with their parents.

\section{DISCUSSION}

With the caveat that our investigation has been restricted to the genera and strains cited, our results indicate that gram-negative bacteria can be divided into four classes on the basis of their observed virulence when the availability of iron is varied (Table XI). Class I pathogens are equally highly virulent in both normal chick embryos and those which have reduced serum iron saturation. Included in this group are strains of $N$. meningitidis, gonococci isolated from disseminated infections, $H$. influenzae type B, E. coli $\mathrm{K}-1, P$. aeruginosa (from septicemic patients), and S. typhimurium. Members of this group generally exhibit a capacity to produce disseminating, septicemic infections although factors other than iron availability may limit expression of this propensity in some hosts. Although not demonstrated in the present study, it is possible, and even expected, that some strains of these species may fall in other classes.

A second group, Class II, consists of pathogens whose virulence is related to the degree of serum iron saturation. Reduction of the relatively high serum iron saturation of chick embryos by administration of the iron-binding protein conalbumin or pretreatment with endotoxin inhibits the growth and virulence of these bacteria. Class II pathogens, such as Shigella, V. cholerae, and most urogenital isolates of $N$. gonorrhoeae, are associated with localized, nondisseminating infections in the normal human host. Members of the third group, Class III, are avirulent mutants which are apparently lacking in the ability to compete for iron, because their virulence for chick embryos was significantly enhanced by exogenous iron. As members of this group have been shown to produce siderophores, their deficiency may be in siderophore utilization. This class includes the avirulent colony types, $\mathrm{T} 3$ and $\mathrm{T} 4$, of gonococci and mutants of $N$. meningitidis, S. flexneri, $E$. coli and $V$. cholerae which differ from the wild type in their inability to absorb the dye Congo red (33). Class IV bacteria, such as the nonpathogenic Neisseria, are avirulent even with added iron and presumably are lacking in other attributes of virulence. 



FIGURE 5 Stimulation of bacterial growth in conalbumin agar. (A) Well contains culture filtrate of Neisseria meningitidis B-11 grown in low-iron medium. Agar seeded with the same strain. (B) Growing culture of Neisseria gonorrhoeae 6555 on surface of conalbumin agar seeded with the homologous strain.

Both Class I and Class II bacteria are apparently capable of acquiring sufficient iron from the normal chick embryo to meet their needs. The already high lethality of these pathogens was not affected by exogenous iron. However, Class II bacteria are apparently limited in their ability to compete for iron and are significantly less virulent in embryos with low serum iron saturation, i.e., levels that are comparable to those in normal human beings.

This suggests that the ability to disseminate requires a greater ability to compete for iron than is required for a superficial infection and, indeed, the disseminating bacteria of Class I appeared to produce greater amounts of siderophores than Class II organisms. The concentration of iron is more closely regulated within the blood and within body tissues than it is on mucosal surfaces. Free iron, available for use by microorganisms, is rarely found in the human body (35). Because food and water serve as a constant source of iron, of which only a small fraction is absorbed by the host (36), much of the dietary iron could be available to microorganisms on mucosal surfaces. Thus, Class II strains, unable to compete under conditions of severe iron restriction, may be provided with sufficient iron for superficial infection. The host may exert some control over the excess iron in the gut by the 
TABLE IX

Bacterial Interactions in Low-Iron Media

\begin{tabular}{|c|c|c|c|c|c|c|}
\hline \multirow[b]{2}{*}{$\begin{array}{l}\text { Indicator } \\
\text { strain }\end{array}$} & \multicolumn{6}{|c|}{ Producer strain } \\
\hline & $\begin{array}{c}N \text {. gonor- } \\
\text { rhoeae } \\
\text { (DGI) }\end{array}$ & $\begin{array}{l}\text { N. menin- } \\
\text { gitidis }\end{array}$ & E. coli & $\begin{array}{l}\text { S. dysen- } \\
\text { teriae }\end{array}$ & $\begin{array}{c}\text { V. chol- } \\
\text { erae }\end{array}$ & $\begin{array}{l}\text { S.typhi- } \\
\text { murium }\end{array}$ \\
\hline N. gonorrhoeae & + & $+*$ & - & $-*$ & $+^{*}$ & - \\
\hline N. meningitidis & - & + & + & $+*$ & + & + \\
\hline E. coli & - & + & + & + & + & + \\
\hline S. dysenteriae & - & + & + & + & + & + \\
\hline V. cholerae & - & + & + & + & + & + \\
\hline S.typhimurium & - & + & + & + & + & + \\
\hline
\end{tabular}

* Inhibitory activity, also present in these culture filtrates, was removed by gel filtration on Sephadex G-10 (Pharmacia Fine Chemicals, Inc., Piscataway, N. J.). Payne, S. M. Unpublished observations.

secretion of the iron-binding protein, lactoferrin, which has been shown to have potent bacteriostatic or bactericidal properties $(3,5)$.

All of the strains tested in this study produced siderophores and these compounds reversed the bacteriostasis induced by iron-binding proteins. Our results, like those of Miles and Kjimji (24) and Luckey
TABLE X

Production of Growth Stimulatory Activity by Gram-Negative Pathogens

\begin{tabular}{lc}
\multicolumn{1}{c}{ Bacterial strain } & Relative activity* \\
\hline N. meningitidis B-11 & 8 \\
N. gonorrhoeae 6555 (DGI) & 2 \\
N. gonorrhoeae CDC 5 & 0.1 \\
E. coli U169 & 16 \\
S. typhimurium & 16 \\
S. dysenteriae WR 377 & 2 \\
V. cholerae 569B & 2 \\
\hline
\end{tabular}

* Expressed as the reciprocal of the highest dilution of the culture filtrate which stimulated growth of the homologous strain in conalbumin agar. $0.05 \mathrm{ml}$ of each dilution was added to wells cut in the seeded agar.

$\ddagger$ Culture filtrate was extracted with ethyl acetate and concentrated 10 -fold by flash evaporation.

et al. (37) demonstrated that these compounds are not species specific: most bacteria could use siderophores produced by a wide variety of microorganisms. Strains of $N$. gonorrhoeae, however, differed from the other bacteria used in this study in this respect and pro-

TABLE XI

Effects of Iron Modification on Gram-Negative Bacterial Pathogens in Chick Embryos

\begin{tabular}{lcc}
\hline CLASS I & \multicolumn{2}{c}{ Virulence unaffected by iron modifications } \\
\cline { 2 - 3 } & \multicolumn{2}{c}{ These strains have an exalted ability to compete for iron, even when } \\
iron availability is restricted. They characteristically are capable of \\
dissemination:
\end{tabular}

Normally virulent in the absence of added iron, these strains are capable of competing for iron except under conditions of low serum iron saturation and generally produce localized, non-disseminating infections:
N. gonorrhoeae $\mathrm{T} 1, \mathrm{~T} 2$
Vibrio cholerae
(most urogenital strains)
Shigella dysenteriae

Shigella flexneri

CLASS III

Virulence enhanced by iron

Relatively avirulent in the absence of added iron:
$N$. gonorrhoeae $\mathrm{T} 3, \mathrm{~T} 4$
N. meningitidis $\mathrm{CR}^{-}$
S. flexneri $\mathrm{CR}^{-}$
E. coli $\mathrm{CR}^{-}$

V. cholerae $\mathrm{CR}^{-}$

CLASS IV Avirulent even with iron supplementation

$\begin{array}{ll}\text { N. sicca } & \text { Y. pestis mutants } \\ \text { N. subflava } & \text { S. flexneri-E. coli hybrid } \\ \text { E. coli K12 } & \end{array}$


duced a siderophore which was apparently specific for gonococci. Neither the closely related meningococcus nor cholera vibrios were able to use this factor despite the fact that culture filtrates of these organisms stimulated growth of gonococci in low-iron medium. ${ }^{3}$ Whether gonococci produce a distinct chemical class of siderophore remains to be determined. The broad spectrum of activity of most of the siderophores suggests the possibility that the normal flora of body surfaces might produce sufficient siderophores to serve the needs of some potential pathogens lacking the ability to produce their own iron-chelating compounds.

The inhibitory effect of iron-binding proteins does not always result in complete cessation of growth, and the protection elicited by conalbumin or LPS treatment of embryos was not absolute. For example, T1 gonococci eventually resumed growth in the presence of conalbumin both in the allantoic cavity and in the blood of infected embryos. It was frequently noted that conalbumin or LPS treated embryos which survived inoculation with one of these pathogens for $24 \mathrm{~h}$ succumbed to the infection by 48-72 h. Incomplete bacteriostasis has also been noted by other investigators $(38,39)$. The long lag period and reduced rate of growth, however, may be sufficient to allow the immunologically competent host to control the infection through other defense mechanisms such as phagocytosis. A relatively high serum iron saturation or administration of exogenous iron may enhance virulence by permitting growth beyond the level which can be controlled by the host.

In addition to its role as an essential nutrient, iron could also affect resistance more subtly by interfering with host defense mechanisms. Phagocytosis appears to be one of the few defenses possessed by the chick embryo at this stage of development (40) and previous studies by Bumgarner and Finkelstein (29) demonstrated an initial clearance of bacteria from the blood which was greater for avirulent than virulent gonococci. Iron has not been shown to affect clearance or phagocytosis of bacteria per se in other experimental infections (3) and it had no effect on the initial clearance of gonococci from the embryo (6).

Interference with intracellular killing by iron may be a more likely possibility. Phagocytic cells contain basic iron-binding proteins and lactoferrin, both of which appear to be important in intracellular killing. Saturation of these proteins with iron reduces their effectiveness in vitro $(41,42)$. Virulent gonococci appear to be more resistant than avirulent cells to intracellular killing (43) and iron may enhance the intracellular survival of the avirulent gonococci. However, it is not

\footnotetext{
${ }^{3}$ Payne, S. M., and R. A. Finkelstein. Infect. Immun. In press.
}

known whether injection of iron can interfere with the killing process within the host.

In summary, our observations indicate that availability of iron is an important determinant not only of virulence, but also of the nature of the infection produced. A consideration of the role of iron in infection and the importance of limiting its availability (44) may be applicable to the treatment of hyperferremic or compromised hosts, whose conditions are frequently complicated by infection. Additionally, bacterial mutants which are unable to compete for iron may be appropriate for use as attenuated vaccines (33).

\section{ACKNOWLEDGMENTS}

This investigation was supported in part by U. S. Public Health Service grants AI-08877 (under the U. S.-Japan Cooperative Medical Science Program) and AI-11278 from the National Institute of Allergy and Infectious Diseases.

\section{REFERENCES}

1. Holmberg, C. G., and C-B. Laurell. 1947. Investigations in serum copper. I. Nature of serum copper and its relation to the iron-binding protein in human serum. Acta Chem. Scand. 1: 944-950.

2. Lönnerdal, B., J. Carlsson, and J. Porath. 1977. Isolation of lactoferrin from human milk by metal-chelate affinity chromatography. FEBS (Fed. Eur. Biochem. Soc.). Lett. 75: 89-92.

3. Bullen, J. J. 1974. Bacterial iron metabolism in infection and immunity. In Microbial Iron Metabolism. J. B. Neilands, editor. Academic Press, Inc. 517-551.

4. Sussman, M. 1974. Iron and infection. In Iron in Biochemistry and Medicine. A. Jacobs and M. Worwood, editors. Academic Press, Inc. 649-679.

5. Arnold, R. R., M. F. Cole, and J. R. McGhee. 1977. A bactericidal effect for human lactoferrin. Science (Wash. D. C.) 197: 263-265.

6. Payne, S. M., and R. A. Finkelstein. 1975. Pathogenesis and immunology of experimental gonococcal infection: role of iron in virulence. Infect. Immun. 12: 1313-1318.

7. Caroline, L. 1974. Brief summaries of a few clinical instances of iron overload. In Microbiology-1974. D. Schlessinger, editor. American Society for Microbiology, Washington, D. C. 270-272.

8. Weinberg, E. D. 1975. Clinical enhancement of nutritional immunity. Compr. Ther. 1: 38-40.

9. McFarlane, H., S. Reddy, K. J. Adcock, H. Adeshina, A. R. Coole, and J. Akene. 1970. Immunity, transferrin and survival in kwashiorkor. Br. Med. J. 4: 268-270.

10. Caroline, L., F. Rosner, and P. J. Kozinn. 1969. Elevated serum iron, low unbound transferrin and candidiasis in acute leukemia. Blood. 34: 441-451.

11. Puschmann, M., and A. M. Ganzoni. 1977. Increased resistance of iron-deficient mice to Salmonella infection. Infect. Immun. 17: 663-664.

12. Kampschmidt, R. F., and H. F. Upchurch. 1962. Effects of bacterial endotoxin on plasma iron. Proc. Soc. Exp. Biol. Med. 110: 191-193.

13. Elin, R. J., and S. M. Wolff. 1974. The role of iron in nonspecific resistance to infection induced by endotoxin. $J$. Immunol. 112: 737-745.

14. Lankford, C. E. 1973. Bacterial assimilation of iron. CRC Crit. Rev. Microbiol. 2: 273-331. 
15. Rogers, H. J. 1973. Iron-binding catechols and virulence in Escherichia coli. Infect. Immun. 7: 445-456.

16. Yancey, R. J., S. A. L. Breeding and C. E. Lankford. 1976. Enterochelin: a virulence factor for Salmonella typhimurium. In Abstracts of the Annual Meeting-1976. American Society for Microbiology, Washington, D. C. 24. (Abstr.)

17. Payne, S. M., and R. A. Finkelstein. 1977. Imferon agar: improved medium for isolation of pathogenic Neisseria.J. Clin. Microbiol. 6: 293-297.

18. Chandler, R. W., R. C. Rendtorff, J. W. Curran, and D. S. Kellogg. 1974. Evaluation of media used for cultures of Neisseria gonorrhoeae and comparison of commercial and laboratory prepared supplements. J. Am. Vener. Dis. Assoc. 1: 14-19.

19. Clowes, R. C., and W. Hayes. 1968. Experiments in Microbial Genetics. John Wiley \& Sons, Inc., New York.

20. Finkelstein, R. A., P. Atthasampunna, M. Chulasamaya, and P. Charunmethee. 1966. Pathogenesis of experimental cholera: biologic activities of purified procholeragen A. J. Immunol. 96: 440-449.

21. Frantz, I. D. 1942. Growth requirements of the meningococcus. J. Bacteriol. 43: 757-761.

22. Willard, J. M., J. J. Davis, and H. G. Wood, 1969. Phosphoenolpyruvate caboxytransphosphorylase. IV. Requirement for metal cations. Biochemistry. 8: 3137-3144.

23. Stookey, L. L. 1970. Ferrozine-a new spectrophotometric reagent for iron. Anal. Chem. 42: 779-781.

24. Miles, A. A., and P. L. Kjimji. 1975. Enterobacterial chelators of iron: their occurrence, detection, and relation to pathogenicity. J. Med. Microbiol. 8: 477-490.

25. Kochan, I., D. L. Cahall, and C. A. Golden. 1971. Employment of tuberculostasis in serum-agar medium for the study of production and activity of mycobactin. Infect. Immun. 4: 130-137.

26. Macham, L. P., and C. Ratledge. 1975. A new group of water-soluble iron-binding compounds from mycobacteria: the exochelins. J. Gen. Microbiol. 89: 379-382.

27. Finkelstein, R. A., and J. P. Ransom. 1960. Non-specific resistance to experimental cholera in embryonated eggs. $J$. Exp. Med. 112: 315-328.

28. Finkelstein, R. A., and G. M. Ramm. 1962. Effect of age on susceptibility to experimental cholera in embryonated eggs. J. Infect. Dis. 11: 239-249.

29. Bumgarner, L., and R. A. Finkelstein. 1973. Pathogenesis and immunology of experimental gonococcal infection: virulence of colony types of Neisseria gonorrhoeae for chicken embryos. Infect. Immun. 8: 919-924.

30. Reed, L. J., and H. Muench. 1938. A simple method of estimating fifty percent endpoints. Am. J. Hyg. 27: 493497.
31. Persijn, J. P., W. van der Slik and A. Riethorst. 1971. Determination of serum iron and latent iron-binding capacity. Clin. Chim. Acta. 35: 91-98.

32. LaBrec, E. H., H. Schneider, T. J. Magnani, and S. B Formal. 1964. Epithelial cell penetration as an essential step in the pathogenesis of bacillary dysentery.J. Bacteriol. 88: 1503-1518.

33. Payne, S. M., and R. A. Finkelstein. 1977. Detection and differentiation of iron-responsive avirulent mutants on Congo red agar. Infect. Immun. 18: 94-98.

34. Finkelstein, R. A. 1961. Alterations in susceptibility of embryonated eggs to Newcastle disease virus by Escherichia coli and endotoxin. Proc. Soc. Exp. Biol. Med. 106: 481484.

35. Bullen, J. J., H. J. Rogers, and J. E. Lewin. 1971. The bacteriostatic effect of serum on Pasteurella septica and its abolition by iron compounds. Immunology. 20: 391406.

36. Cook, J. D., W. E. Barry, C. Hershko, G. Fillet, and C. A Finch. 1973. Iron kinetics with emphasis on iron overload. Am. J. Pathol. 72: 337-343.

37. Luckey, M., J. R. Pollack, R. Wayne, B. N. Ames, and J. B. Neilands. 1972. Iron uptake in Salmonella typhimurium: utilization of exogenous siderochromes as iron carriers. $J$. Bacteriol. 111: 731-738.

38. Bullen, J. J., C. G. Ward, and S. N. Wallis. 1974. Virulence and the role of iron in Pseudomonas aeruginosa infection. Infect. Immun. 10: 443-450.

39. Schade, A. L., and L. Caroline. 1944. Raw hen egg white and the role of iron in growth inhibition of Shigella dysenteriae, Staphylococcus aureus, Escherichia coli and Saccharomyces cerevisiae. Science (Wash. D. C.). 100: 14-15.

40. Board, R. G., and R. Fuller. 1974. Non-specific antimicrobial defences of the avian egg, embryo and neonate. Biol. Rev. Camb. Philos. Soc. 49: 15-49.

41. Gladstone, G. P., and E. Walton. 1970. Effect of iron on the bactericidal proteins from rabbit polymorphonuclear leukocytes. Nature (Lond.). 227: 849-851.

42. Bullen, J. J., and S. N. Wallis. 1977. Reversal of the bactericidal effect of polymorphs by a ferritin-antibody complex. FEMS (Fed. Eur. Microbiol. Soc.). Lett. 1: 117-120.

43. Witt, K., D. R. Veale, and H. Smith. 1976. Resistance to ingestion and digestion of Neisseria gonorrhoeae by phagocytes of human buffy coat. J. Med. Microbiol. 9: $1-12$.

44. Kochan, I. 1977. Role of siderophores in nutritional immunity and bacterial parasites. In Microorganisms and Minerals. Eugene D. Weinberg, editor. Marcel Dekker, Inc., New York. 251-288. 